CORRIGENDUM

\title{
A FROSTMAN-TYPE LEMMA FOR SETS WITH LARGE INTERSECTIONS, AND AN APPLICATION TO DIOPHANTINE APPROXIMATION - CORRIGENDUM
}

\author{
TOMAS PERSSON AND HENRY W. J. REEVE
}

doi.org/10.1017/S0013091514000066, Published by Cambridge University Press, 27 October 2014

Keywords: diophantine approximation; Hausdorff dimension; classes with large intersections; corrigendum

Simon Baker has brought to my attention an error in the proof of Theorem 1.2 of $[\mathbf{1}]$. The theorem states that a set $E_{\lambda}(\alpha)$ belongs to the class $\mathscr{G}^{1 / \alpha}([0,1])$ for almost all $\lambda \in(1 / 2,1)$. In the proof it is established that, for any positive integer $m$, the set $E_{\lambda}(\alpha)$ belongs to $\mathscr{G}^{1 / \alpha}([0,1])$ for almost all $\lambda \in(1 / \sqrt[m]{2}, \sqrt[m]{0.64})$. The mistake is that this sequence of intervals does not cover $(1 / 2,1)$, but only $(1 / 2,0.64) \cup(\sqrt{2} / 2,1)$. In Theorem 1.2 , one should therefore replace 'for almost all $\lambda \in(1 / 2,1)$ ' with 'for almost all $\lambda \in(1 / 2,0.64) \cup$ $(\sqrt{2} / 2,1)^{\prime}$.

\section{Reference}

1. T. Persson and H. Reeve, A Frostman-type lemma for sets with large intersections, and an application to Diophantine approximation, Proc. Edinb. Math. Soc. 58(2) (2015), $521-542$. 